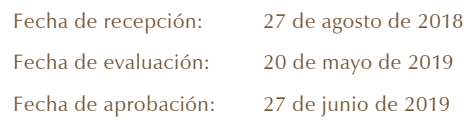

\section{Erika Patricia Alfonso Rosero ${ }^{* *}$}

\title{
La contratación estatal y el posacuerdo en Colombia: un análisis de los contratos plan para la $\mathrm{Paz}^{*}$
}

Para citar este artículo

Alfonso, E. (2019). La contratación estatal y el posacuerdo en Colombia: un análisis de los contratos Plan para la paz. Vía luris, 27, 75-92.

\section{RESUMEN}

La figura de los contratos plan, de origen francés, se convierte en una tipología contractual de especial importancia en el contexto de los acuerdos de paz y su proceso de implementación en Colombia, en razón a que se constituyen en un mecanismo de contratación pública que posibilita la articulación interinstitucional para el desarrollo territorial, la participación de las comunidades y las entidades territoriales, y se convierte así en un facilitador para la descentralización política y económica del país. De esta manera, los contratos plan, en su versión "contratos plan para la paz", esperan hacer posible la reconstrucción política, económica, productiva e infraestructural de los territorios más afectados por el conflicto, así como la potencialización de sus particularidades. En este orden de ideas, este estudio pretende analizar los fundamentos y la operatividad de los contratos plan para la paz en Colombia, como mecanismos de contratación pública en el marco del posacuerdo. La investigación responde a un diseño cualitativo con enfoque exploratorio, de modo que ofrece una sólida reflexión en la que se demuestra cómo los contratos plan para la paz son vehículos de importantes recursos con destino al territorio. Esto permite, por una parte, un nuevo relacionamiento entre entidades territoriales y el Gobierno nacional, y, por otra, su descentralización territorial, acompañada del desarrollo regional desde la participación e incorporación.

* El presente artículo es resultado de la investigación "Análisis de contratos Plan para la Paz" desarrollada en el curso de la Maestría en Contratación Estatal de la Universidad de Medellín, como requisito para optar al título de magíster. El trabajo se realizó en el 2017 bajo la tutoría y la dirección de la Dra. Luz Karime Ángel, docente del programa. Medellín (Colombia).

** Abogada egresada de la Corporación Universitaria Uniciencia, Especialista en Contratación Estatal de la Universidad de Medellín, Especialista en Derecho Laboral de la Universidad Externado de Colombia y candidata a Magíster en Contratación Estatal de la Universidad de Medellín, Medellín (Colombia). ORCID: https://orcid.org/0000-0001-9258-1604. Correo electrónico de contacto: erikaalfonso1@hotmail.com
DOI: https://doi.org/10.37511/viaiuris.n27a4

Esta obra está bajo una Licencia Creative Commons Atribución-CompartirIgual 4.0 Internacional.

\section{Palabras clave}

Contratos plan, contratos plan para la paz,

posacuerdo, contratación pública, coordinación interinstitucional, multinivel, descentralización

territorial. 


\title{
State contracting and the posacuerdo in Colombia: an analysis of the plan for peace contracts
}

\section{Erika Patricia Alfonso Rosero}

\begin{abstract}
The figure of contracts plan of French origin becomes a contractual typology of special importance in the context of the peace agreements and their implementation process in Colombia; given that they constitute a mechanism of public procurement that enables the inter-institutional articulation for territorial development, the participation of communities and territorial entities, becoming a facilitator for the political and economic decentralization of the country. Thus, the Contracts Plan in its Contracts Plan for Peace version, hope to make possible the political, economic, productive and infrastructural reconstruction of the territories most affected by the conflict, as well as the potentialization of its particularities. In this order of ideas, this study intends to analyze the fundamentals and operativeness of the contracts plan for peace in Colombia, as public procurement mechanisms in the framework of the post-agreement. The research responds to a qualitative design with an exploratory approach, which offers a solid reflection in which it is demonstrated how the covenants plan for peace, are vehicles of important resources destined to the territory, allowing on the one hand, a new relationship between territorial entities and the national government, and on the other, their territorial decentralization, accompanied by regional development from participation and incorporation.
\end{abstract}

\section{Keywords}

Contracts plan, contracts plan for peace, agreement, public contracting, interinstitutional coordination, multilevel, territorial decentralization. 


\section{A contratação do Estado e \\ o posacuerdo na Colômbia: \\ uma análise dos contratos \\ do plano para a paz}

\section{Erika Patricia Alfonso Rosero}

\section{RESUMO}

A figura do plano de contratos de origem francesa, torna-se uma tipologia contratual de especial importância no contexto dos acordos de paz e seu processo de implementação na Colômbia; dado que constituem um mecanismo de compras públicas que possibilita a articulação interinstitucional para o desenvolvimento territorial, a participação de comunidades e entidades territoriais, tornando-se um facilitador para a descentralização política e econômica do país. Assim, o Plano de Contratos, em sua versão do plano de contratos para a paz, visa possibilitar a reconstrução política, econômica, produtiva e infra-estrutural dos territórios mais afetados pelo conflito, bem como a potencialização de suas particularidades. Nesta ordem de idéias, este estudo pretende analisar os fundamentos e operatividade do plano de contratos para a paz na Colômbia, como mecanismos de compras públicas no âmbito do pós-acordo. A pesquisa responde a um desenho qualitativo com uma abordagem exploratória, que oferece uma reflexão sólida em que se demonstra como os "convênios planejam a paz", são veículos de importantes recursos destinados ao território, permitindo por um lado, um novo relacionamento entre entidades territoriais e o governo nacional e, por outro lado, sua descentralização territorial, acompanhada de desenvolvimento regional de participação e incorporação. 


\section{Les contrats d'État et le posacuerdo en Colombie: analyse des contrats du plan de paix}

\section{Erika Patricia Alfonso Rosero}

\section{RÉSUMÉ}

La figure du plan de contrats d'origine française devient une typologie contractuelle d'une importance particulière dans le contexte des accords de paix et de leur processus de mise en œuvre en Colombie; étant donné qu'ils constituent un mécanisme de passation des marchés publics qui permet l'articulation interinstitutionnelle pour le développement territorial, la participation des communautés et des entités territoriales, devenant ainsi un facilitateur de la décentralisation politique et économique du pays. Ainsi, le plan des contrats dans sa version plan des contrats pour la paix espère permettre la reconstruction politique, économique, productive et infrastructurelle des territoires les plus touchés par le conflit, ainsi que la potentialisation de ses particularités. Dans cet ordre d'idées, cette étude se propose d'analyser les principes fondamentaux et le caractère opérationnel du plan de passation des marchés pour la paix en Colombie, en tant que mécanismes de passation des marchés publics dans le cadre de l'après-accord. La recherche répond à une conception qualitative avec une approche exploratoire, qui offre une solide réflexion dans laquelle il est démontré que le "plan des pactes pour la paix" est un vecteur d'importantes ressources destinées au territoire, permettant, d'une part, une nouvelle relation. entre les entités territoriales et le gouvernement national et, d'autre part, leur décentralisation territoriale, accompagnée d'un développement régional issu de la participation et de l'incorporation. 


\section{INTRODUCCIÓN}

Los contratos plan se definen como figuras contractuales a través de las cuales se establece una forma de armonización entre los procesos de gestión de la nación y de las entidades territoriales, de modo que permiten conectar la planeación estatal y el presupuesto nacional. En efecto, según el Departamento Nacional de Planeación (DNP), Conpes 3822 (2014), los contratos plan se sitúan como procesos de descentralización, así como un mecanismo de inversión multinivel, lo que en Colombia supone otorgarle un enfoque territorial.

Desde esta perspectiva, se podría estimar que los contratos plan en Colombia son instrumentos relativamente nuevos, en la medida en que su marco jurídico se ubica en la Ley 1454 de 2011, por la cual se crea como un acuerdo de voluntades entre las instituciones y las entidades territoriales, luego regulado por medio del Decreto 819 de 2012, en el que se propone un marco base para su suscripción, ejecución y evaluación. Dos años más tarde, los contratos plan hacían parte fundamental del Plan Nacional de Desarrollo del expresidente Juan Manuel Santos 2014-2018, definidos como mecanismos estratégicos para la contratación como vía de desarrollo territorial, a la par de confluir en procesos de articulación Estado-territorio. Con los acuerdos de paz, este tipo de contratos se proponen como instrumentos fundamentales en la consolidación de la paz territorial y el planteamiento de políticas públicas para el posconflicto (Departamento Nacional de Planeación, 2017a).

Efectivamente, por medio de los contratos plan y su segunda etapa, contratos plan para la paz, se asume en Colombia una nueva modalidad de contratación pública para el aprovechamiento de recursos que permite el mejoramiento de la inversión, lo que influye necesariamente en la creación de estrategias de planeación nacional y regional. Estas características implican avances significativos en la capacidad institucional para la creación de proyectos, la incrementación de recursos para obras públicas y, en efecto, el afianzamiento de los modelos, así como de los de inversión territorial y su respectiva descentralización regional. Subyace a este campo el incremento en la competitividad regional a través de la potenciación de las economías y los mercados locales, los progresos de infraestructura educativa, hospitalaria y vial, lo cual propicia en los territorios la conectividad y el desarrollo tecnológico. Desde esta perspectiva, la pregunta que direcciona este artículo se plantea lo siguiente: ¿Cuál es el fundamento y la operatividad de los contratos plan para la paz como mecanismos de contratación en el marco del posacuerdo?

Así, el propósito del artículo de reflexión responde a lo que se podría denominar "una baja producción textual acerca de los contratos plan para paz", solventada aquí bajo dos perspectivas: una desde el aspecto de la forma y la otra desde el aspecto de la profundidad. El primero, el aspecto formal, implica visibilizar la relevancia que establecen los contratos plan para la paz desde postulados tales como la planificación estratégica y la construcción de la paz, la posibilidad de fortalecer y construir tejido social y la coordinación interinstitucional como capacidad de fortalecimiento del Estado y la sociedad civil. La segunda, la perspectiva de profundidad, implica establecer cómo es el funcionamiento de estos contratos, es decir, lo referente a su operatividad, la cual va desde su fundamento normativo, los mecanismos y los procedimientos, hasta su relación en el posacuerdo.

Al considerar estos factores, el presente artículo de reflexión tiene por objetivo analizar el fundamento y la operatividad de los contratos plan para la paz como mecanismos de contratación en el marco del posacuerdo. En concordancia, el objetivo se desarrolló en tres objetivos concretos: relacionar elementos históricos y normativos, y el surgimiento de estos en las políticas públicas nacionales como modelos piloto en algunos departamentos colombianos; establecer un análisis del desarrollo operativo y el funcionamiento general de este tipo específico de contratos desde características tales como actores, tipologías, mecanismos, fondos, etc.; y, finalmente, reflexionar sobre la relación de los contratos plan para la paz, el posconflicto y la contratación como fundamento de la consolidación de la paz en los territorios.

\section{METODOLOGÍA}

La metodología del artículo de reflexión responde a un diseño cualitativo que se define como un proceso de reseñar y analizar las principales características de los fenómenos sociales y jurídicos (Galeano, 2004):

Dada la naturaleza del método cualitativo, el diseño configura un marco fijo e inmodificable, 
sino un punto de referencia que indica que se va a explorar (objetivos), como debe procederse (la estrategia) y que técnicas se van a utilizar (la recolección). Aunque se espera que el diseño se vaya ajustando durante el proceso, ninguna etapa debe iniciarse sin tener claramente delimitados el qué, el cómo y una apreciación tentativa de los resultados eventuales. (Monje, 2011, p. 16)

El enfoque es exploratorio, entendido este como una forma de aproximación y familiarización de una temática poco abordada con la finalidad de aumentar los grados de conocimiento (Hernández, Fernández \& Baptista, 2006) en este caso, el fundamento y la operatividad de los contratos plan para la paz en el país como mecanismos de contratación en el marco del posacuerdo.

Dentro de las técnicas de recolección de la información se encuentran:

- Análisis bibliográfico. Presenta los resultados obtenidos de libros, textos y artículos que puedan acercarse al objeto de la investigación.

- Análisis documental. Fundamentalmente, considera los textos de carácter institucional y gubernamental como la fuente principal de proceso de recolección.

De esta manera, los instrumentos de recolección de la información se demarcaron por medio de un análisis bibliográfico y documental.

\section{RESULTADOS Y DISCUSIÓN}

Los resultados se presentan en tres partes fundamentales. La primera plantea el abordaje histórico y político de los contratos plan, lo cual incluye su génesis europea y su demarcación institucional, sus alcances y sus límites. En un segundo aspecto, los resultados consolidan el procesamiento jurídico, así como la relación entre políticas públicas y contratación en Colombia, lo que permite evidenciar su legitimidad en el orden del factor territorial y su reconstrucción socioeconómica municipal. Finalmente, el artículo estima los dispositivos — jurídicos y operativos - que permiten desglosar los objetivos y la funcionalidad de los contratos plan en el contexto del posacuerdo.

\section{Contratos plan y sus orígenes franceses}

Según Navarre y Honorario (2016), los contratos plan se crearon en 1984, en Francia, denominados como "contratos Estado-regiones"1. Su función era establecer ciertos objetivos estratégicos para la función pública que, por una parte, articulaban el desarrollo territorial y la financiación de los proyectos locales, y, por otra, conectaban las entidades territoriales con el Estado.

En este sentido, se asumía un esfuerzo conjunto entre el Estado francés y las instituciones regionales, lo cual generaba procesos de cofinanciación de proyectos y mantenimiento de economías de escala. Según autores como Navarre y Honorario (2016), los contratos plan franceses se caracterizaron por conectar tres objetivos específicos: el primero, cambiar el esquema "unilateral" predominante en las inversiones públicas, de manera que se permitía la operatividad y la acción conjunta; el segundo, construir una herramienta que permitiera articular y alinear el plan nacional y los planes locales; y, finalmente, construir un instrumento que propicie el diálogo y la gobernanza, además de proveer servicios públicos a la totalidad del territorio.

En efecto, la generación de contratos Estado-regiones le permitió al Estado establecer una posibilidad más amplia de elegir y actuar sobre programas específicos que, en función de una visión estratégica, generaban formas de cooperación, planeación y financiación entre el Estado y las instituciones territoriales². Según López (2013), gracias a esto fue posible distribuirlo en varias generaciones de tipologías de contratos, desde su creación hasta la actualidad:

1 "La ley de la descentralizaci6n de 1982 — que prosigue ella misma unas tentativas de organización económica regional que remontan a los años 1960 y a la creación de la Delegación para la organización del territorio y la acción regional (DATAR) (14) en 1964- establece en ese momento nuevas reglas de juego. Los 'contratos de plan' Estado-regiones, negociados entre interlocutores supuestamente autónomos, sustituyen el "partenariado" y las codecisiones contractuales a la gestión jacobina descendiente" (Desrosières ,1996, p. 12).

2 “En 1982 tendría lugar la descentralización política y la de carácter científico, coincidiendo con la internacionalización de las economías regionales. Así como la elaboración de los primeros contratos plan entre el Estado y la región. Y un año después, 1983, se pondría en marcha la política de creación de las tecnópolis o parques de tecnología de punta, rompiendo con la idea de desarrollo por la base originando un gran debate nacional sobre el papel del Estado en la ordenación del territorio elitista de carácter urbano y regional (Jordá Borrell,1992, p. 43). 
- Tipología 1. Articulación Estado-entidades territoriales.

- Tipología 2. Entorno europeo y mercado único (generación de empleo, cohesión y adaptación al mercado europeo).

- Tipología 3. Se transforman en planes quinquenales a través de consejos nacionales y de organismos territoriales (búsqueda del equilibrio regional).

- Tipología 4. Mejoramiento de la integración Estado-región y contextualización al escenario de la Unión Europea, mediante la optimización de los sistemas de financiación.

Para Matallana (2013), los contratos plan son aún un mecanismo efectivo de contratación multinivel en Francia, en cuanto herramienta de articulación territorial, comunitaria y estatal, situación que, en efecto, ha contribuido a que este país brinde su colaboración a través de capacitaciones y asesoramientos técnicos a funcionarios en Colombia sobre elementos teóricos y prácticos de los contratos, así como recomendaciones para su mejoramiento $y$ aplicabilidad en el contexto del posconflicto. De otra parte, y según cuentas estimadas por el Ministerio de Hacienda (2017), la Agencia Francesa para el Desarrollo ha destinado 200.000 euros para el primer contrato plan y las capacitaciones.

\section{Contratos plan en el ordenamiento colombiano}

Los contratos plan surgen en Colombia a través de la Ley 1450 de 2011, específicamente en el artículo 8, a su vez modificado por el artículo 198 de la Ley 1753 de 2015. Si bien se concibió como un mecanismo relativamente novedoso, se ha consolidado como un instrumento que prioriza la eliminación de las brechas interdepartamentales, importante en la minimización de la pobreza y el fortalecimiento institucional en los territorios del país.

En esencia, la Ley 1753 de 2016, por medio de la cual se expide el Plan Nacional de Desarrollo 20142018 "Todos por un nuevo país", define de manera expresa los contratos plan en su artículo 198 en los siguientes términos:

Un acuerdo marco de voluntades de carácter estratégico entre la nación y las entidades territoriales plasmado en un documento que contiene los arreglos programáticos y de desempeño definido entre estas para la ejecución asociada de proyectos de desarrollo territorial que contemplen la concurrencia de esfuerzos de inversión nacional y territorial. (Ley 1753 de 2015, art 198)

Como característica particular, la misma ley establece que los contratos plan son documentos concretos y específicos, demarcados por el objeto, las metas, los plazos, las responsabilidades y los recursos tanto nacionales como territoriales que se destinan para su respectiva ejecución. Posteriormente, la norma desarrolla la obligatoriedad de establecer con claridad los procesos de seguimiento, control y evaluación, articulados precisamente a las particularidades de cada territorio o región.

En efecto, se constituyen así desde el marco normativo en un instrumento que articula los planes nacionales de desarrollo (PND) y los planes tanto departamentales como municipales, de manera que propicia cierta "armonía" entre objetivos estatales o gubernamentales, así como el desarrollo, mediante la participación de los territorios. Además, la norma fija la responsabilidad que posee el Departamento de Planeación Nacional (DNP) tanto en la aplicación de este tipo de contratos como en su seguimiento y control.

En el artículo 199 de esta misma Ley se establecen los mecanismos para la ejecución de los contratos plan. En principio, la normativa crea una nueva entidad como responsable de la gestión de los recursos para este tipo de contratación, definido como el Fondo Regional para los Contratos Plan (FRCP), adscrito efectivamente al Departamento de Planeación Nacional (DPN) y administrado por una entidad financiera de carácter nacional, con efectiva participación estatal. Los recursos que este fondo obtiene provienen de varias fuentes y se destinan a su ejecución.

Otra característica que cabe resaltar en la perspectiva normativa de la Ley 1753 de 2015, en este tipo de contratos, es la necesidad del Gobierno nacional en la generación de incentivos. Efectivamente, el gobierno crea la denominada "bolsa de recursos" como una fuente de incentivos para el cumplimiento de las metas y los objetivos de los contratos plan ejecutados. El incentivo funciona como "premio" y motivación en el cumplimiento efectivo de las 
metas y como garantía institucional para un desarrollo constante.

Cabe también resaltar la Ley 1454 de 2011, la cual establece un compendio normativo sobre el ordenamiento territorial que comprende la aplicabilidad de contratos plan. De manera concreta, este tipo de contratación se ve inmersa en dos artículos en particular: en el artículo 18, sobre "los contratos y los convenios plan", en la cual se establece la posibilidad de que la nación pueda contratar y convenir con entidades territoriales o asociaciones de entidades territoriales en procesos de ejecución de diferentes proyectos para el desarrollo territorial; los contratos plan suscritos deben contener en sí mismos los procesos de financiación y sus fuentes respectivas. En segundo lugar, se encuentra el artículo 20 denominado "delegación", en el cual se establece la posibilidad de emerger modelos de "asociación" territoriales y departamentales, a la vez de profundizar en formas delegativas para entidades nacionales, territoriales e instituciones descentralizadas (Ley 1454 de 2011).

Con respecto a los contratos plan referenciados en el Plan de Desarrollo 2014-2018³ , se configuran como uno de los mecanismos de gestión y de asignación de recursos más relevantes que se evidencian en tres componentes: alinear objetivos gubernamentales, articular fuentes y recursos, y permitir un incremento en las inversiones regionales y municipales. Se conciben a sí mismos como instrumentos novedosos que parten de procesos de estandarización con entidades internacionales tales como la Organización para la Cooperación y el Desarrollo Económico (OCDE), cuyo proyecto de planificación implica formas de cogestión entre lo económico, lo social y lo ambiental.

Los contratos plan se encuentran articulados, de manera general, en el Plan de Desarrollo (2014-2018), en tres ejes preponderantes de la gestión estatal:

- Transporte público. Como eje estructurador de la movilidad y como instrumentos que gestionan los

3 Asimismo, "en el Plan Nacional de Desarrollo 2010-2014 'Prosperidad para todos' establece en los principios rectores del ordenamiento territorial, dentro del principio de economía y buen gobierno, la conformación de esquemas asociativos en los que se optimice el gasto público, en los cuales, los contratos plan, se constituyen en herramienta de asociación (González, 2013. p. 313). aportes para municipios, así como la definición de los elementos de movilidad endógena y exógena.

- Red hospitalaria. Se sitúan como formas de inversión pública hospitalaria y articuladores de "condiciones eficientes" para el fortalecimiento de los territorios en la prestación de servicios de salud.

- Seguridad. Los contratos plan se estiman como mecanismos de fortalecimiento de las entidades territoriales, tales como la Policía Nacional y, en efecto, como fuentes de financiación para su fortalecimiento.

En concordancia, los contratos plan aparecen como parte de la responsabilidad gubernamental en el compromiso de fortalecer los territorios y la construcción de una paz duradera, de modo que se establecen como una herramienta elemental en la adecuación y preparación institucional. Bajo esta perspectiva, se puede observar en este Plan Nacional de Desarrollo (2014-2018) algunos de los principios y procesos con miras a las políticas públicas para el posconflicto:

El Gobierno nacional, en desarrollo de los principios de coordinación, concurrencia y subsidiariedad, podrá suscribir acuerdos con las entidades territoriales para la planificación de visiones de paz y desarrollo sostenibles, en el mediano y largo plazo, con un enfoque participativo y territorial. En el marco de estos procesos de planificación, se privilegiará la celebración de contratos plan o contratos interadministrativos, APP, entre otros mecanismos, donde podrán concurrir diferentes fuentes de financiación y en los cuales se establezcan las obligaciones y compromisos necesarios para la ejecución de políticas públicas orientadas a la construcción de paz en los territorios. (Presidencia de la República, 2014, p. 527)

De acuerdo con lo determinado por el Plan Nacional de Desarrollo (2014-2018), los contratos plan articulados al tema de la paz tendrán en su elaboración claves tales como:

- Planificación estratégica para la construcción de paz. Se consideran apuestas institucionales por espacios en los que el conflicto se desarrolló en diferentes dimensiones y cuya capacidad institucional fue mínima o precaria. Se plantean, 
por ende, nuevas dinámicas de construcción de políticas públicas territoriales que incluyan efectivamente la participación social y las iniciativas desde las organizaciones sociales. Las iniciativas tendrán como garantía acciones prioritarias para la respectiva asignación de recursos, lo que permita un acompañamiento significativo, así como el fomento de la participación civil.

- Fortalecimiento del tejido social y la integración. Permitirá una serie de "acciones integrales" que contribuyan a la potenciación de ofertas sociales dirigidas a las poblaciones más afectadas, sea en el marco del conflicto armado, o por la propia estructura económica del país. Efectivamente, la participación plural y democrática de los territorios asume un conocimiento concreto de las dificultades y los problemas de diferente índole que serán parte del accionar del contrato.

- Coordinación institucional. Busca generar procesos de articulación entre entidades e instituciones estatales para la adjudicación de recursos estratégicos en lo que respecta al modelo de justicia transicional, acuerdos institucionales, reparación y marcos normativos, entre otros.

De acuerdo con el Departamento de Planeación Nacional (2017a), los contratos plan constituyen el denominado "nuevo enfoque" entre la articulación nación-territorio, caracterizado por una innovación en la lógica de planeación con enfoque territorial y enfoque funcional como ejercicio piloto en el que han participado nueve departamentos (Arauca, Boyacá, Cauca, Nariño, Santander, Tolima, Antioquia, Córdoba y Chocó). En efecto, en la apuesta efectuada en estos departamentos, los contratos plan han sido entendidos desde la lógica teórica y pragmática como instrumentos contractuales para acordar importantes modelos de financiación y recursos, y, por ende, a fin de establecer resultados concretos entre los acuerdos nación-territorio, lo cual ha permitido — según el PND - constituirlo como un instrumento de escalamiento institucional.

Ciertamente, parte del objetivo general establecido en el PND para los contratos plan se formula como mecanismo para promover la planeación concertada y la gobernanza multinivel. Se busca, por tanto, el mejoramiento en los niveles de coordinación entre Estado- territorio, lo cual propicie la generación de relaciones estratégicas que incluyen la posibilidad de ampliarse en las ciudades capitales.
Dos características son elementales y esenciales de los contratos plan en el PND. La primera, el rango temporal; esto, desde una perspectiva prioritaria y, por ende, de mediano plazo para el desarrollo territorial. La segunda, el enfoque social, en la medida en que busca la minimización y la eliminación de brechas socioeconómicas a través de una serie de propuestas de impacto enmarcadas en inversiones de infraestructura, inversión productiva y mejoramiento de la capacidad institucional, creación e innovación de instrumentos con mayor eficiencia e incentivos en el cumplimiento de metas de los contratos. En efecto, es responsabilidad gubernamental, en el propósito de cumplir con el objetivo general de los contratos plan y llevar a cabo sus dos características esenciales, continuar con la creación de esquemas normativos y financieros que permitan la eficacia de su ejecución.

Cabe resaltar que la creación e innovación de instrumentos con un grado superior de eficacia, en parte, se relaciona con el impacto que generan los contratos plan desde la arista de la integración regional, la asociatividad departamental y territorial, la planeación cooperativa entre departamentos, su ejecución multinivel y, finalmente, la posibilidad de conectar corredores de comercio exterior como parte de la política de mejoramiento comercial y productiva.

Por último, los contratos plan hacen parte de un aumento significativo y cada vez mayor de articulación entre el Estado-territorio, el Gobierno y la sociedad civil, lo cual inscribe su realidad material en la coordinación del Plan Nacional de Desarrollo y los planes departamentales y municipales.

\section{Operatividad y mecanismos multinivel de los contratos plan}

En el texto "Contratos plan, manual operativo", el Departamento Nacional de Planeación (2011) aclara y precisa sobre el aspecto operante de este tipo de contratos. En principio, se concibe como una forma de coordinación interinstitucional y un elemento fundamental para la construcción de territorio. Desde esta dinámica, los contratos plan establecen acuerdos en tres aspectos: i. Objetivos, se fundamenta en el desarrollo de manera holística para los ciudadanos y como parte de la preponderancia del mejoramiento de sus medios; ii. Proyectos, se caracteriza por propender a la ejecución de planes que permitan solventar necesidades a corto y mediano plazo; 
iii. Recursos, mediante los cuales se específica la estimación y las fuentes de financiación.

Cabe señalar que los contratos plan no se conciben ni como acuerdo marco, en tanto los socios y firmantes adquieren compromisos mutuos y una firma previa de "acta de compromiso", ni se deben entender como convenio interadministrativo, en tanto estos últimos establecen modalidades de prestación conjunta de servicios públicos, mientras que los contratos plan se conciben como acuerdos estratégicos. De la misma manera, no se considera un mecanismo de ejecución de presupuestos sectoriales (por ejemplo, este tipo de contratos no establece planificaciones por ministerios, sino por necesidades territoriales bajo la acción pública).

\section{Actores en los contratos plan}

Ahora bien, en lo que concierne a los actores, la elaboración de los contratos plan los conciben como responsables políticos y legales, y, a su vez, con una participación plural que abarca al Gobierno, las empresas privadas, las organizaciones territoriales, las entidades, etc., y los distribuye en firmantes, facilitadores y copartícipes (véase la tabla 1).

\section{Tipologías de contratos plan}

Efectivamente, como lo ha expresado tanto la normativa como el propio PND, los contratos plan adquieren preponderancia en la medida en que articulan la nación y el territorio, de modo que permiten la participación de una pluralidad de entidades a nivel territorial, desde sus capacidades y potencialidades, por lo cual se han establecido una serie de tipologías de contratos plan. Se plantean, en esa medida, tres tipos generales de contrato: a) contratos plan nación departamento (CPND), b) contratos plan nación territorios pertinentes (CPTP), y c) contratos plan nación esquemas asociativos (CPEA) (véase la tabla 2).

\section{El contrato plan como mecanismo multinivel}

Los contratos plan implica comprenderlos como mecanismos de coordinación y articulación entre los diferentes niveles de la construcción de Estado, desde el espacio territorial, municipal, departamental, los territorios asociativos y a nivel nacional. Esta forma de coordinación interinstitucional supone la posibilidad de generar acuerdos estratégicos en una

Tabla 1. Actores en los contratos plan

\begin{tabular}{|c|c|c|}
\hline Firmantes & Facilitadores & Copartícipes \\
\hline $\begin{array}{l}\text { 1. De la nación } \\
\text { Suscriben este tipo de contratos } \\
\text { las diferentes entidades a nivel } \\
\text { nacional cuyos firmantes serán } \\
\text { los representantes: ministros, } \\
\text { viceministros, directores, gerentes, } \\
\text { etc. } \\
\text { 2. Entidades territoriales } \\
\text { Suscriben este tipo de contratos } \\
\text { los diferentes municipios, } \\
\text { departamentos y, tal como } \\
\text { lo estableció la Ley orgánica } \\
\text { de ordenamiento territorial, } \\
\text { esquemas asociativos cuyos } \\
\text { firmantes serán los representantes } \\
\text { (alcaldes, gobernadores, gerentes, } \\
\text { etc.). } \\
\text { Autoridades ambientales } \\
\text { Suscriben este tipo de contratos } \\
\text { las diferentes corporaciones } \\
\text { autónomas regionales o quien } \\
\text { realice su función. }\end{array}$ & $\begin{array}{l}\text { 1. De la nación } \\
\text { La financiación, en su mayoría } \\
\text { efectuada por el presupuesto } \\
\text { general de la nación con dos } \\
\text { entidades, fundamentalmente: } \\
\text { - Departamento Nacional de } \\
\text { Planeación: procesos de } \\
\text { coordinación de iniciativas, } \\
\text { propuestas, desarrollo y } \\
\text { control. } \\
\text { - Fondo Financiero de } \\
\text { Proyectos de Desarrollo: } \\
\text { asistencia técnica, } \\
\text { coordinación administrativa, } \\
\text { ejecución. } \\
\text { 2. Entidades territoriales } \\
\text { Cumplen funciones tales } \\
\text { como iniciativa, preparación, } \\
\text { administración, evaluación, } \\
\text { estructuración y ejecución con } \\
\text { los diferentes representantes de } \\
\text { los organismos territoriales. }\end{array}$ & $\begin{array}{l}\text { 1. Cuerpos colegiados y sector } \\
\text { empresarial } \\
\text { Los concejos municipales y las } \\
\text { asambleas departamentales tienen } \\
\text { como función aprobar también los } \\
\text { documentos para la planeación } \\
\text { local (tanto a nivel de desarrollo } \\
\text { como territorial), por lo cual proce- } \\
\text { sos tales como la autorización de } \\
\text { presupuestos son fundamentales en } \\
\text { la ejecución de los contratos plan. } \\
\text { Se le suma a este aspecto dos } \\
\text { actores locales que contribuyen } \\
\text { de diferentes maneras a la } \\
\text { consolidación del plan: } \\
\text { - Sector empresarial: a través } \\
\text { de una participación público- } \\
\text { privada. } \\
\text { - Ciudadanía: procesos de } \\
\text { participación, información, } \\
\text { evaluación y, en definitiva, } \\
\text { rendición de cuentas. }\end{array}$ \\
\hline
\end{tabular}

Fuente: DNP (Departamento Nacional de Planeación). (2011). Contratos plan, manual operativo. Grupo de Comunicaciones y Relaciones Públicas. 
Tabla 2. Tipologías de contrato

\begin{tabular}{|c|c|c|}
\hline $\begin{array}{c}\text { Contratos plan nación departamento } \\
\text { (CPND) }\end{array}$ & $\begin{array}{c}\text { Contratos plan nación territorios } \\
\text { pertinentes (CPTP) }\end{array}$ & $\begin{array}{c}\text { Contratos plan nación esquemas } \\
\text { asociativos (CPEA) }\end{array}$ \\
\hline $\begin{array}{l}\text { Se considera un nivel intermedio a través } \\
\text { del cual se coordina el Gobierno nacional } \\
\text { y el territorio. Su objetivo, por ende, } \\
\text { es coordinar la oferta del Estado en el } \\
\text { territorio y que, efectivamente, partan de } \\
\text { las necesidades locales. } \\
\text { Se plantean tres componentes para este } \\
\text { contrato: } \\
\text { - Los CPND potencian las características } \\
\text { departamentales en lo tocante a } \\
\text { concurrencia y subsidiariedad, de } \\
\text { modo que permiten el apoyo local y } \\
\text { profundizan en el nivel técnico. } \\
\text { - Los CPND establecen un modelo } \\
\text { de integración en los niveles } \\
\text { subnacionales, en articulación con los } \\
\text { planes de desarrollo departamental. } \\
\text { - Los CPND desarrollan una visión } \\
\text { territorial en la cual se priorizan } \\
\text { necesidades y potencialidades a fin de } \\
\text { establecer la capacidad de desarrollo. }\end{array}$ & $\begin{array}{l}\text { Los CPTP posibilitan la generación } \\
\text { de esquemas flexibles en la } \\
\text { administración lo cual permite } \\
\text { la pluralidad territorial, así como } \\
\text { el mejoramiento de la presencia } \\
\text { de las instituciones del Estado y } \\
\text { la priorización de medidas para } \\
\text { las necesidades sociopolíticas, } \\
\text { económicas y productivas en los } \\
\text { territorios. } \\
\text { De la misma manera, permite la } \\
\text { coordinación interinstitucional, } \\
\text { por medio de la cual y de manera } \\
\text { concreta articula posibilidades de } \\
\text { participación ciudadana. }\end{array}$ & $\begin{array}{l}\text { LOS CPEA se proponen como } \\
\text { coordinación de voluntades de } \\
\text { las entidades territoriales, en la } \\
\text { cual, la asociación y el desarrollo } \\
\text { interno propician una construcción } \\
\text { acorde al desarrollo territorial } \\
\text { y a una planificación "de abajo } \\
\text { arriba", es decir, desde lo territorios. } \\
\text { Efectivamente, este tipo de contrato } \\
\text { plan requiere un proceso de unidad } \\
\text { y cierta visión articulada de los } \\
\text { territorios. } \\
\text { Esta dinámica asume nuevos } \\
\text { postulados para entender los } \\
\text { contratos en cuanto permite } \\
\text { potenciar la asociatividad, } \\
\text { el aislamiento político o } \\
\text { administrativo, asume componentes } \\
\text { de complementariedad y da cuenta } \\
\text { de las especificidades del contexto } \\
\text { en el territorio (cultural, social, } \\
\text { político, etc.). }\end{array}$ \\
\hline
\end{tabular}

Fuente: DNP (Departamento Nacional de Planeación). (2011). Contratos plan, manual operativo. Grupo de Comunicaciones y Relaciones Públicas.

multiplicidad de entidades e instituciones, cuyos niveles de autonomía los demarca el concepto legal y se convierten en una exigencia de gestión política.

El proceso de coordinación es de suma relevancia en el propósito de comprender los contratos plan como mecanismos multinivel, para lo cual se debe entender la integralidad de sus componentes. Efectivamente, a nivel nacional existe la necesidad de articular la oferta, en la cual, por ejemplo, es el Departamento Nacional de Planeación el que establece temas tales como la iniciativa, la solicitud y la oferta de proyectos. En una escala local, plantean las posibilidades de asociatividad territorial enmarcadas, fundamentalmente, por una prestación conjunta de servicios y una delegación de atribuciones propias. Finalmente, se encuentra la coordinación multinivel, por medio de la cual se logran articular planes de desarrollo nacionales, territoriales y municipales, entre otros.

\section{Etapas y procedimiento del contrato plan}

Como ya se fundamentó, la reglamentación que establece el funcionamiento del contrato plan se encuentra en la Ley 1753 de 2015, pero, de manera concreta, su operatividad se encuentra en el Manual operativo de contratos plan (Departamento Nacional de Planeación, 2011). Las etapas para la generación del contrato plan se distribuyen en la precontractual, contractual y poscontractual de la siguiente manera:

- Etapa precontractual. Se caracteriza por cuatro procesos: la iniciativa, en el que se relaciona la entidad territorial y se realiza la publicidad; la solicitud, en la cual se conecta el Departamento Nacional De Planeación y la entidad territorial; la elaboración, en el que se plantea el acuerdo estratégico sobre el desarrollo territorial al establecer el diagnóstico, el plan de acción y los indicadores; $y$, finalmente, se suscribe el acta de compromiso, mediante la cual se establecen las partes, el objeto, el documento visión, el cronograma y las consecuencias.

- Etapa contractual. Se caracteriza por suscribir el contrato. Este precisa de contenido, documentos soportes, suscripción, firmas, ejecución, delegación, fuentes de financiación, arreglos institucionales e incentivos. Entre la epata precontractual y la etapa contractual se estiman mecanismos de evaluación y rendición de cuentas.

- Etapa poscontractual. Caracterizada por la liquidación y la evaluación, en ella se establecen 
modificaciones, la evaluación referencia, los resultados e impactos.

Cabe resaltar, en este aspecto, que el inicio de la etapa precontractual de los contratos plan es la parte fundamental para dar inicio a la estructuración de los proyectos; es, además, preponderante que en esta etapa, aunque no se encuentre en la gráfica, la formulación debe encontrarse bajo los parámetros de Fonade.

Bajo esta perspectiva, la operatividad de los contratos plan incide necesariamente en la consolidación de sus propios objetivos como instrumentos estratégicos e, incluso, como métodos de contratación que tienen en cuenta especificidades y capacidades de los territorios, tratándose, por tanto, de una lectura alternativa del funcionamiento contractual del Estado.

\section{DISCUSIÓN}

La presente discusión se relaciona con la pregunta orientadora sobre el fundamento y la operatividad de los contratos, desarrollada en los resultados. Así, pues, la discusión se asume como posibilidad de relacionar dicha fundamentación y operatividad en los marcos de la realidad social y política del país, en clave con la contratación pública, así como sus condiciones particulares dentro del desarrollo del posacuerdo.

\section{Contratos plan para la paz: entre el posconflicto y la contratación pública}

En el 2016, el Gobierno nacional, en vista de los resultados, la eficacia y la eficiencia de los contratos plan y el contexto de implementación de acuerdos y el posconflicto, optó por que este tipo de acuerdos contractuales fueran los instrumentos precisos para focalizar y articular los diferentes niveles del Estado en la inversión pública para el restablecimiento institucional, el desarrollo territorial y la descentralización en los territorios más afectados por el conflicto, de acuerdo con lo estipulado por el Departamento Nacional de Planeación (2017).

Los contratos plan para la paz se consideran, por ende, una "segunda etapa" de los contratos plan en general. Así, pues, según Beltrán (2016), el espacio denominado "posconflicto" asume una serie de dificultades que no solo atañen al desmonte de las estructuras armadas ilegales o a su respectiva desmovilización, sino a los cambios y trasformaciones en torno a las instituciones colombianas que permitan la erradicación de la violencia en el país. En este sentido, con el proceso de implementación de acuerdos y la profundización de la paz, los contratos plan para la paz surgen como amplios mecanismos de inversión y focalización sectorial.

Desde esta perspectiva, los contratos plan para la paz tienen como objetivo desarrollar procesos de inversión regional y territorial en zonas que han sido históricamente afectadas por cuenta del conflicto, y desde allí permitir que la inversión pública contribuya al mejoramiento integral de los municipios del país. Cabe resaltar que la figura general para la financiación de estos contratos se distribuye en un $60 \%$ de aporte del gobierno y un $40 \%$ de los entes territoriales.

Según Santos Alonso Beltrán, gerente nacional de contratos plan del Departamento de Planeación Nacional (2018), los contratos plan para la paz se asumen desde hace algún tiempo —en los discursos y en las prácticas institucionales - como una herramienta de profundización de la paz y vehiculización de cambios sustanciales a nivel territorial. Efectivamente, la inversión pública efectuada a través de este tipo de mecanismos subyace a la posibilidad de mejorar componentes fundamentales de los municipios y departamentos, de manera que se genera autonomía, no desde la centralización del Gobierno, sino desde las necesidades concretas y específicas, es decir, como soluciones a las demandas sociales, políticas y económicas de las comunidades. De allí que la finalidad de estos contratos sea la construcción y el mejoramiento de infraestructura (educativa, hospitalaria, vial, servicios públicos), además de garantizar la presencia del Estado colombiano.

Una parte elemental del análisis de los contratos plan para la paz es establecer la articulación de los principios constitucionales y los principios de la contratación estatal colombiana, lo cual propicie una estructuración de proyectos en diálogo interinstitucional, con plena participación de entidades locales y organizaciones civiles $y$, por ende, adecuados a la inversión pública, de una manera más eficaz ${ }^{4}$.

4 La eficacia se ha propuesto como uno de los principios fundamentales en la contratación estatal colombiana, preponderante en los contratos plan para la paz a fin de cumplir los objetivos públicos, y relacionado, fundamentalmente, a "hacer las cosas de la mejor forma (eficientemente),", bajo las dinámicas temporales y espaciales determinadas. En este caso, la eficacia se determina como un principio de la gestión administrativa 
En el 2016 se firma el primer contrato plan para la paz en los departamentos de Bolívar y Sucre (con énfasis en los montes de María). Este contrato, considerado el primero de esta categoría del posconflicto, es producto de un análisis de los principales indicadores sociales y económicos, lo que evidencia la relación que existe entre los efectos del conflicto armado y las brechas sociales, económicas y de infraestructura. Desde esta perspectiva, la utilización de estos contratos, en este contexto específico, establece en principio la articulación entre el Gobierno nacional, el gobierno municipal y el DPN, y potencia así las características particulares, tales como el sector agropecuario, minero, pesquero, artesanal y turístico. ${ }^{5}$.

Un año más tarde, en el 2017, se firma el segundo contrato plan para la paz en el departamento del Valle, el cual funcionó en treinta y cuatro municipios, y en el que se hizo referencia a programas para agua potable, construcción vial, proyectos de vivienda, desarrollo agrícola, infraestructura y seguridad, todo con la finalidad de profundizar mecanismos de mejoramiento institucional local en el marco para el posconflicto. Como segundo aspecto, en este caso, los contratos plan tienen como especificidad mejorar la competitividad del municipio, conectarlos y modernizarlos ${ }^{6}$.

En este mismo año, según la Presidencia de la República (2017), se firman los contratos paz en los departamentos del Meta y el Guaviare. En el Meta se realiza una inversión pública por un billón cuatrocientos cincuenta millones, con lo cual se intenta financiar un aproximado de ciento ochenta proyectos de "alto impacto", vinculados, principalmente, al desarrollo económico y social del departamento. Son veintinueve los municipios beneficiados con esta tipología contractual, determinados como los más

moderna al garantizar otros principios, como, por ejemplo, el de legalidad o celeridad, así como el cumplimiento de las metas propuestas (Atehortúa, Hernández y Marino, 2010, p. 50).

5 Este Contrato Plan tendrá vigencia de seis años y contempla inversiones en agua potable y saneamiento básico por COP 332665 millones, vías COP 885758 millones, educación, COP 229694 millones, salud y protección social COP 222000 millones, vivienda COP 113766 millones, ambiente y desarrollo sostenible COP 85123 millones, sector agropecuario COP 63090 millones, inclusión social cOP 56732 millones, deporte y recreación COP 9600 millones.

6 Este contrato tiene una inversión de COP 2,8 billones de pesos, de los cuales se caracterizan inversiones particulares del territorio como plan frutícola de COP 30000 millones, construcción de tanques de almacenamiento de COP 34615 millones y recuperación ambiental con COP 59000 millones (DNP, 2017b, p. 48). afectados por el conflicto armado interno. Entre los "proyectos de priorización" se encuentran: proyectos de energía solar, construcción de redes eléctricas rurales, conexiones viales rurales y cascos urbanos, y mejoramiento de infraestructura vial (sobre todo, en vías terciarias).

En el Guaviare, los contratos plan para la paz, según Moreno (18 de enero de 2018), tienen por objetivo la financiación de ciento cincuenta y nueve proyectos de alto impacto distribuidos en los cuatro municipios. Los proyectos se caracterizan por potenciar sectores tales como la infraestructura en vivienda y acueducto, la infraestructura vial, el sector agropecuario e inclusión social, todos componentes resultantes de las especificidades del departamento.

Ciertamente, con la firma de estos contratos plan se inicia un proceso innovador en Colombia en el que factores como particularidad, especificidad y potenciación son categorías fundamentales que permiten vincular los escenarios micro y macropolítico, así como metodologías de articulación y vinculación contractual. Llama la atención también el "tratamiento diferencial" relacionado, principalmente, con la planeación de los contratos en entornos geográficos que antes de las negociaciones de paz constituían focos de violencia y exclusión, en los que la capacidad de gestión en inversión pública era precaria o nula. En estos términos, el tratamiento diferencial coadyuva necesariamente a una lectura del entorno de los territorios y prioriza las demandas y necesidades de las comunidades, se minimiza el aislamiento producto del conflicto y se disponen los recursos públicos y privados para una intervención positiva.

Así, según el Departamento Nacional de Planeación (2016), los contratos plan profundizan en la democratización de la inversión pública si se atiende a la "focalización" que estos promueven y desarrollan, distribuida en:

- Focalización de los contratos. Permite que se aborden desde ejes programáticos, mediación de los niveles de impacto, diagnósticos de las estructuras económicas y productivas de crecimiento, a la par de complementar los esfuerzos fiscales de los territorios.

- Focalización geográfica. Trabaja en territorios distintos y en una pluralidad de niveles, de modo que establece capacidades de potenciación 
de sectores determinados, armonización entre prioridades territoriales y asignación de recursos, estructuración de formas multinivel de gobierno e inclusión geográfica.

- Focalización por sectores o temas. Su propósito contractual es complementar otras formas de inversión adjudicadas a los municipios, por medio de las cuales se logran inversiones sociales, productivas y económicas, además del fortalecimiento del énfasis de las instituciones y las entidades locales.

- Focalización programática. En esta se desarrolla la denominada "visión presupuestal moderna", la cual tiene un énfasis en la planeación y la evaluación, definida, principalmente, por el carácter de los resultados, así como en una conexión entre los planes generales, como, por ejemplo, los nacionales, departamentales o territoriales, aquellos que son sectoriales y los planes específicos, medidos en función de sus resultados.

- Focalización en la financiación. Como posibilidad de lograr fuentes de financiación e inversiones verificables que distribuyan el presupuesto nacional y departamental, e incentiven la participación privada controlada y limitada, por lo cual la verificación de la gestión debe responder a parámetros constantemente evaluados y monitoreados.

\section{Contratos plan: contexto del acuerdo final para la terminación del conflicto, implementación y desarrollo}

Como se ha venido estableciendo, los contratos plan para la paz han constituido una de las herramientas fundamentales no solo para la implementación del acuerdo final para la terminación del conflicto y la construcción de una paz estable y duradera con las FARC (2016), sino también para adecuar y dar operatividad a los recursos del posconflicto con miras a su sostenimiento y desarrollo.

Desde esta perspectiva, lo siguientes son algunos hallazgos que permiten demostrar el avance y el desarrollo de este tipo de contratos:

Relacionamiento entre entidades territoriales y Gobierno nacional: los contratos plan para la Paz establecen un nuevo marco de posibilidades desde la perspectiva institucional. Tanto la inversión pública como la toma de decisiones no presuponen una relación de centro en la que el Gobierno nacional tome las decisiones absolutas o unilaterales. Así como los mecanismos, los contratos plan para la paz son en sí mismos medios para canalizar los recursos y las decisiones en un rango más amplio y con mayor participación, lo que incluye también el sector privado. Aparte de esto, el relacionamiento entre entidades territoriales y Gobierno nacional supone un fortalecimiento mutuo, con especificidades en las entidades territoriales y municipales, de modo que interconecta de mejor manera sus decisiones y crea así formas de coordinación.

- Descentralización territorial. Los contratos plan para la paz fundamentan una nueva dinámica en los que la participación de las entidades territoriales y las comunidades son fundamentales. La descentralización, como mecanismo político, económico y administrativo ${ }^{7}$, constituye una distribución de la riqueza y de la inversión que permite a los territorios tomar decisiones propias en lo referente a la utilización o adjudicación de dichas inversiones. Con la descentralización no se busca un proceso de autonomía a gran escala de los municipios o territorios, sino, por el contrario, propone la disminución de brechas de pobreza y aislamiento, así como una forma de correlación competitiva referenciada desde la particularidad productiva y las potencialidades de cada territorio ${ }^{8}$.

- Desarrollo regional. Con los contratos plan para la paz se posiciona un nuevo discurso en torno al aislamiento y la exclusión de varias zonas del país que, en principio, se veían afectadas por el conflicto armado como centros de violencia y desarticulación entre la sociedad civil y el Estado. Con este tipo de contratos el desarrollo territorial crece en la medida en que estas zonas se convierten en focos de inversión pública importante, de modo que mejoran las dimensiones sociales, culturales y económicas de los territorios.

- Relacionamiento entre comunidad y gobierno multinivel. Con los procesos de descentralización de

7 Establecido por la Constitución de Colombia de 1991, en los arts. 1 y 287 (este último hace referencia a la autonomía administrativa de las entidades territoriales).

8 "A la figura de los contratos plan, la precede 'un debate largo sobre el proceso y herramientas de la descentralización territorial en Colombia'" (González, 2013 p. 308). 
los territorios y de inversión conjunta se coordinan intereses nacionales, departamentales y municipales, así como de las comunidades. En tanto, se profundiza la descentralización en el marco de estos contratos, la autonomía y la respectiva participación territorial, institucional y comunitaria se desdobla, a fin de verificar las necesidades y los déficits históricos de los municipios, tema que da preponderancia a la incorporación de la sociedad civil en la institucionalidad.

- Desarrollo de servicios sociales y presencia estatal. Como parte de la segunda generación de contratos plan, los contratos plan para la paz suponen un instrumento que permite fortalecer la implementación de los acuerdos y, por ende, actuar como base del posconflicto. Esto implica que la inversión y ejecución en estos territorios establezca la presencia estatal no solo en lo que se refiere a la Fuerza Pública, sino a través de la vehiculización de servicios sociales: educación, salud, infraestructura, proyectos productivos, agua potable, seguridad, alcantarillado, redes eléctricas, recreación, vivienda, comunicación y tecnología, entre otros.

En esencia, con el desarrollo de los contratos plan y de los contratos plan para la paz, en un marco histórico, se ha dado un mejoramiento continuo en los territorios y las comunidades, lo que ha permitido una potencialización de proyectos y una adjudicación de recursos preponderantes en el país. Según Cárdenas (2019), el comparativo entre los contratos plan y los contratos plan para la paz evidencia un aumento significativo en la aplicación y su impacto para la territorialidad y la nación en tan solo cinco años:

- Los contratos plan han estimado, en el departamento de Arauca, ciento treinta y tres proyectos, en Boyacá doscientos doce proyectos, en Santander cuarenta y un proyectos, en Atrato ciento sesenta y siete proyectos, en Tolima noventa y cuatro proyectos, en norte del cauca setenta y cinco proyectos, y en Nariño ciento cuarenta y nueve proyectos.

- Los contratos plan para la paz han desarrollado proyectos: Bolívar, quinientos cuarenta y cuatro, Valle del cauca doscientos setenta, Caquetá ciento noventa y seis, Meta ciento ochenta y uno, Guaviare ciento cincuenta y nueve, y Guainía ochenta y dos proyectos.
En estos términos, cabe resaltar que los contratos plan se sitúan en la dinámica de eliminar las brechas de pobreza interdepartamentales, mientras que los contratos plan para la paz suponen un impacto en zonas afectadas por el conflicto (de allí la cantidad diferencial de proyectos aplicados).

Finalmente, Según Moreno (2018), una parte sustancial del análisis sobre los contratos plan para la paz no solo confluye en evidenciarlos como acuerdos contractuales de adjudicación de recursos, sino en relación profunda con la paz y el "destierro de la violencia". Es este punto que la incidencia y el impacto de estos contratos establecen su fortaleza y propósito, pues es una forma práctica de vincular las categorías de desarrollo y paz. La eliminación de la violencia se relaciona no solo con el proceso mismo de negociación, sino con la implementación que les permite a las comunidades excluidas política, económica y socialmente participar y fortalecer sus instituciones desde lo territorial, municipal, departamental y hasta nacional. Efectivamente, como herramienta, los contratos plan para la paz coadyuvan y son parte de una integralidad para que el posconflicto sea una realidad en el país, y posibiliten reformas profundas tanto en su producción, operatividad y evaluación como en sus resultados.

\section{CONCLUSIONES}

El fundamento y la operatividad de los contratos plan para la paz permiten referenciar las nuevas posibilidades que la contratación pública colombiana genera, en la medida en que la implementación del acuerdo final y el marco del posacuerdo plantean nuevos desafíos a la gestión contractual, el funcionamiento estatal y la relación con la sociedad civil. En efecto, el universo que se abre en el campo de lo público adquiere preponderancia en tanto se vincula y articula una serie de necesidades territoriales que van desde la infraestructura vial, los servicios sociales y la productividad local hasta el desarrollo departamental, temas hoy neurálgicos en los que la administración pública considera respuestas innovadoras e inéditas en el contexto del país.

Esto refleja la importancia de los contratos plan para la paz no solo como mecanismos contractuales, sino como posibilidades importantes de participación integral — tanto política como económica- de las comunidades, lo cual sustente la paz desde los escenarios micro en los que estos mecanismos se desarrollan. De allí la relevancia de su fundamento, 
operatividad y relación con el posacuerdo, y, por ende, lo necesario de su compresión social y política.

La investigación demostró que los contratos plan han generado procesos interesantes en relación con la cofinanciación y el desarrollo regional, al cambiar esquemas de centralización gubernamental y de inversión pública. Desde esta perspectiva, el fundamento normativo realiza un acople importante de esta estructura de contratación en la Ley 1450 y 1454 de 2011, así como en la 1753 de 2015, por el cual se fortalece este tipo de relaciones contractuales en virtud de la eliminación de brechas interdepartamentales, la mitigación de la pobreza, el desarrollo territorial y la presencia estatal. Con este fundamento normativo se plantea la posibilidad de articular proyectos y planes territoriales, departamentales y nacionales como elementos de cogestión económica, política y ambiental. En efecto, una parte fundamental del desarrollo legislativo de los contratos plan se enmarca en relación con una planificación estratégica como sostenimiento de la paz, así como del fortalecimiento e integración de la sociedad y la coordinación interinstitucional.

Entre los hallazgos en función de lo operativo, el artículo evidenció los contratos plan para la paz como mecanismos de multinivel por medio de los cuales se coordinan las instituciones, los recursos y las comunidades. La relación, por ende, de los actores (firmantes, facilitadores y copartícipes) se caracteriza por brindar legitimidad y marcos operativos específicos desde las entidades territoriales, así como de las departamentales, e insiste siempre desde la perspectiva de la paz y el desarrollo ambiental. La operatividad, por tanto, oscila en la escala y la capacidad de organización y coordinación entre los contratos plan nación departamento (CPND), los contratos plan nación territorios pertinentes (CPTP) y los contratos plan nación esquemas asociativos (CPEA) como evidencia de la perspectiva multinivel.

En relación con los hallazgos que articulan los fundamentos, la operatividad y el marco del posacuerdo de esta tipología contractual, el artículo evidenció la eficiencia y la eficacia de la articulación gubernamental en los multiniveles y, por ende, el proceso de descentralización tanto de la inversión como de la ejecución de los contratos. En ese caso, desde la generación de los contratos plan pilotos, hasta la puesta en marcha de los contratos plan para la paz en los departamentos de Bolívar, Sucre, Valle, Meta y el Guaviare, se evidencia un proceso innovador a partir del tratamiento diferencial de los departamentos históricamente afectados por el conflicto armado, el desafío de posicionar la paz y el reto de potencializar las capacidades específicas de cada uno de los territorios. Con la aplicabilidad de los contratos plan para la paz emerge, por una parte, la democratización de la inversión pública; por otra, surgen los enfoques con los cuales se atienden las necesidades propias de los territorios y los departamentos.

En fin, es claro que los contratos plan para la paz son instrumentos vehiculizadores de importantes recursos con un enfoque de paz y sostenimiento. En este tipo de contratos confluye un nuevo relacionamiento entre entidades territoriales y Gobierno nacional, la descentralización territorial, el desarrollo regional desde la participación e incorporación de las necesidades y las comunidades, los relacionamientos en torno a un gobierno multinivel, el desglosamiento de servicios sociales y presencia estatal, así como una gestión contractual ligada a la profundización de la paz y el posacuerdo. 


\section{REFERENCIAS}

Atehortúa, C., Hernández, A. y Marino, J. (2010). Temas en contratos estatales. Medellín: Biblioteca Jurídica Duke.

Cárdenas, A. (2019). Contratos Plan se concentran en proyectos de alto impacto. Revista Portafolio. Recuperado de: https://www.portafolio.co/ economia/contratos-plan-se-concentran-enproyectos-de-alto-impacto-528312

Desrosiéres, A. (1996). Reflejar o instituir: La invención de los indicadores estadísticos. En Jornadas de estudio. París: Observatorio Interregional de lo Político. Asociación Francesa de Ciencia Política. pp. 189-205.

DNP (Departamento Nacional de Planeación). (2011). Contratos plan, manual operativo. Grupo de Comunicaciones y Relaciones Públicas.

DNP (Departamento Nacional de Planeación). (2017a). Contratos paz. Distribución geográfica. Disponible en https://www.dnp.gov.co/ Contratos-Plan/Paginas/ContratosPlan.aspx

Departamento Nacional de Planeación. (2017b). Contrato paz del Valle prevé inversiones por $\$ 2,8$ billones para afianzar la paz. Recuperado de https://www.dnp.gov.co/Paginas/ Contrato-Paz-del-Valle-prev\%C3\%A9-inversiones-por-\$2,8-billones-para-afianzar-la-paz. aspx

DNP (Departamento Nacional de Planeación). (2018). Así va el avance del programa Contratos Plan para la Paz. DNP.

El Colombiano. (16 de mayo de 2016). Firmarán ocho contratos plan para el postconflicto. Recuperado de http://www.elcolombiano. com/colombia/firmaran-ocho-contratos-planpara-el-posconflicto-MK4149709
González, D. (2013). Consideraciones jurídicas sobre la figura de los contratos plan en Colombia. En L. Estupiñan y M. A. Restrepo (eds.), Asociatividad territorial. Enfoque comparado y análisis en el nuevo contexto de la organización territorial (pp. 307-335). Universidad del Rosario.

Hernández, Fernández \& Baptista. (2006). Metodología de la Investigación. McGraw-Hill. México.

Jordá Borrell, R. M. (1992). Modernización tecnológica como estrategia de desarrollo para Andalucía. Revista de Estudios Andaluces, (18), 27-68.

Ley 1450 de 2011. Por la cual se expide el Plan Nacional de Desarrollo, 2010-2014. Junio 16 de 2011. DO 48.102.

Ley 1454 de 2011. Por la cual se dictan normas orgánicas sobre ordenamiento territorial y se modifican otras disposiciones. Junio 26 de 2011. DO 48.115.

Ley 1753 de 2015. Por la cual se expide el Plan Nacional de Desarrollo 2014-2018 "Todos por un nuevo país". Junio 9 de 2015. Do 49.538.

López, G. (2013). La contratación directa en Colombia. Popayán: Corporación Universitaria Autónoma el Cauca.

Matallana, E. (2013). La contratación y la contratación estatal. Bogotá: Universidad Externado de Colombia.

Ministerio de Hacienda. (2017). Francia y Colombia firman convenio de crédito por 200 millones de euros para el desarrollo rural en el postconflicto. Recuperado de http://www. minhacienda.gov.co/HomeMinhacienda/ ShowProperty?nodeld=\%2FOCS\%2FP_MHCP WCC-098784\%2F\%2FidcPrimaryFile\&revisio $\mathrm{n}=$ latestreleased 
Moreno, J. (18 de enero de 2018). Los contratos plan y el destierro de la violencia. Revista Portafolio. Recuperado de http://www.portafolio.co/ economia/los-contratos-paz-y-el-destierrode-la-violencia-513411

Navarre, F. y Honorario, P. (2017). La experiencia francesa de los contratos plan Estado-regiones En Contratos plan. Un instrumento para la descentralización y el desarrollo de regiones. Bogotá: DNP.

Revista Portafolio. (2016). Montes de María firma el primer contrato para el posconflicto por
\$2,3 millones. Recuperado de: https://www. portafolio.co/economia/gobierno/contratoposconflicto-firmo-montes-maria-497825

Presidencia de la República. (2014). Plan Nacional de Desarrollo 2014-2018. Bogotá: Presidencia de la República.

Presidencia de la República. (2017). Firmados contratos paz, por 1,9 billones de pesos, para Meta y Guaviare. Recuperado de: http:// es.presidencia.gov.co/noticia/171027-Firmados-Contratos-Paz-por-1-9-billones-depesos-para-Meta-y-Guaviare 